\title{
TOLERÂNCIA AGUDA E CRÔNICA À SALINIDADE DE JUVENIS DE PANGASIUS (Pangasianodon hypophthalmus)
}

\author{
GIZ, Amarilys Macari de ${ }^{1}$ \\ SQUASSONI, Gustavo Henrique \\ MONTEZUMA, Lucas Valentin \\ CORONEL, Andrés Manuel de Jesús Leguizamón, \\ SILVA, Janaina Della Torre da \\ DIAS, Luciana Thie Seki
}

\begin{abstract}
RESUMO: Especula-se que a produção comercial de pangasius seja viável em viveiros ou tanques abastecidos com água salobra, apresentando-se como uma alternativa na região semiárida do Brasil, notadamente reconhecida pela sua escassez de água potável. Diante disto, o intuito deste experimento foi avaliar a tolerância aguda e crônica de juvenis de pangasius submetidos a diferentes salinidades. Foram utilizados 216 juvenis de pangasius $(17,30 \pm 5,26 \mathrm{~g})$, distribuídos em delineamento inteiramente casualizado, com quatro tratamentos e quatro repetições. Para o ensaio de toxicidade aguda foram testadas quatro salinidades $(5 ; 10 ; 12,5$ e $15 \%$ ) e um tratamento controle (água doce - $0 \%$ ). Baseado nos resultados obtidos no ensaio de tolerância aguda determinou-se as concentrações salinas utilizadas no ensaio de tolerância crônica: 5; 7,5 e 10\% e controle (0\%). Neste ensaio foram avaliados parâmetros de crescimento (peso e comprimento, ganho de peso, consumo de ração e taxa de mortalidade) e parâmetros físico-químicos da água (temperatura, $\mathrm{pH}$ e amônia tóxica). Adicionalmente observações visuais foram realizadas para detectar possíveis alterações morfológicas ou comportamentais decorrentes da exposição às diferentes salinidades. A salinidade letal média (SL50) para o pangasius nas condições do estudo foi estimada em 10,76\% (IC 95\% = 10,22 - 11,33\%o). Maiores taxas de ganho de peso $(\mathrm{p}<0,05)$ foram observadas nas faixas de salinidade de 5 e $7,5 \%$. Não foram verificadas diferenças $(\mathrm{p} \geq 0,05)$ entre as médias de peso, comprimento final e nos parâmetros físico-químicos da água nas concentrações salinas estudadas. Alterações morfológicas e comportamentais foram detectadas nos peixes do tratamento controle e nas salinidades de 7,5 e 10\%o. Os resultados encontrados sugerem que o pangasius apresenta relativa tolerância à salinidade. Entretanto, é necessário um aprofundamento de estudos de campo sobre a real influência da salinidade para esta espécie, buscando avaliar os possíveis efeitos sobre o crescimento ao longo de todo o ciclo produtivo, para que seja possível determinar o real potencial de cultivo nestas condições.
\end{abstract}

Palavras-chave: Crescimento; Estresse; Peixes; Sal; Sobrevivência

\section{ACUTE AND CHRONIC SALINITY TOLERANCE IN JUVENILES OF PANGASIUS (Pangasianodon hypophthalmus)}

SUMMARY: It is believed that the commercial production of pangasius is viable in ponds or tanks supplied with saline water, as an alternative for the semi-arid region in Brazil, known for its scarcity of drinking water. In this sense, the objective of this experiment was to evaluate the acute and chronic tolerance of juvenile pangasius submitted to different salinities. 216 juveniles pangasius $(17.30 \pm 5.26 \mathrm{~g})$ were distributed in a completely randomized design, with four treatments and four replicates. For the acute toxicity test, four salinities $(5 ; 10 ; 12.5$, and $15 \%$ ) and a control treatment (fresh water - 0\%o) were tested. Based on the results obtained in the acute toxicity test, saline concentrations for the chronic tolerance test were determined: $5 ; 7.5$ and 10\%o and control (0\%). In this trial, fish growth parameters (weight, length, weight gain, feed intake, and mortality rate) and water physicochemical parameters (temperature, $\mathrm{pH}$, and toxic ammonia) were evaluated. Additionally, visual observations were made in order to observe morphological or behavioral changes due to exposure to different salinities. Mean lethal salinity (SL50) for pangasius under the study conditions was estimated at 10.76\% (95\% CI $=10.22-11.33 \%$ o). Higher weight gain rates ( $\mathrm{p}<0.05$ ) were observed between 5 and $7.5 \%$ salinity ranges. No differences $(\mathrm{p} \geq 0.05)$ were observed among average weight, final length and physicochemical parameters of water at the salt concentrations studied. Morphological and behavioral changes were detected in fish from control treatment and salinities 7.5 and $10 \%$. Results suggest that pangasius presents a relative tolerance to salinity. However, it is necessary to deepen field studies on the real influence of salinity on this species, aiming at evaluating the possible effects on growth throughout productive cycle, so that it is possible to determine the real potential of cultivation under these conditions.

${ }^{1}$ Universidade Federal de São Carlos (UFSCar)

Nucleus, v.12, n.1, maio 2020 
Keywords: Fish, growth, salt, stress, survival

\section{INTRODUÇÃO}

O pangasius (Pangasianodon hypophthalmus) (SAUVAGE, 1878), popularmente conhecido no Brasil como panga, vem sendo considerado um dos destaques da aquicultura mundial, por apresentar uma série de características zootécnicas desejáveis como: facilidade de manejo e cultivo, altas taxas de crescimento, hábito alimentar onívoro, boa eficiência alimentar, e características desejáveis do filé como cor, textura e ausência de espinhas intramusculares, com boa aceitação pelo mercado consumidor (KADER et al., 2011).

Trata-se de uma espécie que se desenvolve bem em ambientes tropicais com temperaturas elevadas (PHUONG ; OANH, 2010), sendo o Brasil um país com excelente potencial para o seu cultivo. Este peixe já vem sendo explorado comercialmente no país há algumas décadas por aquariofilistas, no entanto, como peixe de corte é importado em grandes quantidades do Vietnã, na forma de filé. Observando as características produtivas do pangasius no continente asiático e mediante o grande potencial produtivo em águas brasileiras, o Estado de São Paulo foi o pioneiro a regulamentar o cultivo desta espécie (Decreto $n^{\circ} 62.243$, de 1 novembro de 2016), para fins comerciais em condições de viveiros escavados com controle de escape. Na Região Nordeste, o cultivo de pangasius foi recentemente regulamentado nos Estados do Rio Grande do Norte (Lei no 10.321, de 8 de Janeiro de 2018) e Sergipe (Resolução no 17/2018, de 18 de julho de 2018).

De acordo com alguns autores, o pangasius demonstra ser uma espécie relativamente tolerante a diferentes faixas de salinidade de água (CASTANEDA et al., 2010; NGUYEN et al., 2014; NGUYEN et al., 2017; KUMAR et al., 2017), despertando grande interesse econômico, notadamente em regiões semiáridas do Brasil, no qual encontram-se grande número de viveiros abastecidos com águas salinizadas, e atualmente inativos devido ao surto do vírus da síndrome da mancha branca (WSSV) que dizimou a produção de camarões destes reservatórios.

A utilização de água salgada (constituída principalmente por $\mathrm{NaCl}$ ) já é amplamente empregada na forma de banhos terapêuticos como um modo de redução do estresse decorrente do manejo e de prevenção aos agentes patogênicos (WURTS, 1995; CARNEIRO; URBINATI, 2001; URBINATI; CARNEIRO, 2006; TAVARES-DIAS; MONTAGNER, 2015), por estimular a produção de muco na pele e brânquias, constrição dos filamentos branquiais e reduzir os níveis de amônia no sangue dos peixes (KUBITZA, 2007), evitar o desenvolvimento de bactérias que podem reduzir os níveis de oxigênio e produzir metabólitos tóxicos (AMEND et al., 1982), além de se apresentar como alternativa ao uso de quimioterápicos, propiciando desta maneira 
sustentabilidade ao ambiente aquático e melhor condição de higidez dos peixes (CHAGAS et al., 2012).

A tolerância à salinidade da água é variável dependendo da espécie de estudo, sendo que o tempo de exposição é um dos fatores determinantes para sua avaliação. De acordo com Saoud et al. (2007), estudos de tolerância à salinidade da água para peixes são fundamentais para a utilização do sal com eficácia e segurança em aquicultura.

Diante do exposto, o presente trabalho teve como objetivo avaliar os possíveis efeitos da exposição aguda e crônica a diferentes salinidades sobre o desenvolvimento de juvenis de pangasius (Pangasianodon hypophthalmus).

\section{MATERIAL E MÉTODO}

O experimento foi conduzido no Centro de Ciências Agrárias na Universidade Federal de São Carlos (UFSCar), na cidade de Araras-SP, (altitude de $692 \mathrm{~m}$; latitude $22^{\circ} 21^{\prime} 25^{\prime \prime} \mathrm{S}$ e longitude $47^{\circ} 23^{\prime} 03^{\prime}$ W). O ensaio foi realizado no período de 20 de janeiro a 16 de maio de 2018, em conformidade às normas editadas pelo Conselho Nacional de Controle da Experimentação Animal (CONCEA), e aprovado pela Comissão de Ética no Uso de Animais (CEUA - Protocolo n ${ }^{\circ}$ 1833080218) da Universidade Federal de São Carlos.

No total, foram utilizados 216 juvenis de pangasius (Pangasianodon hypophthalmus) (peso

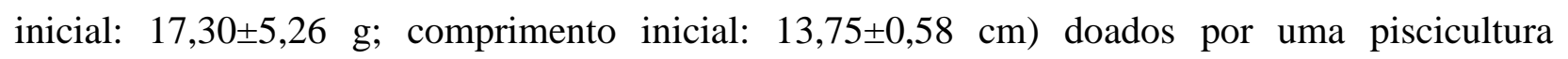
comercial. Noventa e seis peixes foram distribuídos igualmente em aquários de vidro $(50$ x $30 \mathrm{x}$ $36 \mathrm{~cm}$ ) com volume útil de 35 litros, em regime semi-estático, com renovação parcial de água (10\% em dias alternados), sem aeração artificial, e mantidos em ambiente controlado em relação à luminosidade e temperatura. Com relação aos parâmetros de água, a temperatura $\left(24,9 \pm 1,1{ }^{\circ} \mathrm{C}\right)$ foi avaliada diariamente, enquanto o $\mathrm{pH}(7,4 \pm 0,5)$ e a concentração de amônia tóxica $(0,08 \pm 0,1$ ppm) foram mensurados semanalmente. Os valores de amônia tóxica foram calculados a partir dos valores de amônia total, de acordo com metodologia proposta por Emerson et al. (1975). O fotoperíodo foi de 12 horas de luz e 12 horas de escuro.

Os peixes foram submetidos previamente a 30 dias de aclimatação às condições experimentais, sendo alimentados com dieta comercial formulada (36\% de proteína bruta; 2-3 $\mathrm{mm}$ de diâmetro do pellet), em uma frequência de três vezes ao dia ( $8 \mathrm{~h} ; 12 \mathrm{~h}$ e $18 \mathrm{~h})$, até saciedade aparente, e, ao final deste período foram mensurados o peso e o comprimento inicial de cada indivíduo. 
Foram realizados dois ensaios distintos, um avaliando a toxicidade aguda e outro a tolerância crônica de juvenis de pangasius expostos a diferentes concentrações de salinidade de água.

Para a determinação das salinidades letais foi realizado um ensaio de toxicidade aguda, com duração de 96 horas, de acordo com a metodologia proposta por Reish ; Oshida (1987). Inicialmente 96 peixes foram distribuídos igualmente em 16 aquários experimentais (6 peixes/aquário). Durante este período de exposição os peixes foram mantidos em jejum. Após o choque osmótico, os aquários foram monitorados constantemente para identificação dos peixes afetados pelo teste e retirada dos animais mortos. Inicialmente foram propostas três salinidades: 5; 10 e 15\% de sal marinho sintético (Blue treasure ${ }^{\circledR}$ - Reef Sea Salt) e um tratamento controle ( $0 \%$ - Água doce), contudo, ao verificar que a concentração salina de 15\%o foi letal aos peixes em um intervalo de 24 horas, estipulou-se um novo tratamento com concentração de 12,5\% de sal.

Com auxílio do programa "Trimmed Spearman-Karber" (HAMILTON et al., 1977) foram estimadas a salinidade letal média (SL50) e o intervalo de confiança (IC 95\%), utilizando os dados de mortalidade registrados para cada concentração salina. A relação entre mortalidade e a salinidade foi descrita por um modelo quadrático, com auxílio do software Microsoft Excel (14.0.6).

Baseado nos resultados obtidos no ensaio de toxicidade aguda determinou-se as concentrações a serem utilizadas no ensaio de tolerância crônica à salinidade: 5; 7,5 e 10\%o, e um controle ( $0 \%$ - água doce), cada um com quatro repetições. O experimento foi conduzido por um período de 90 dias em aquários de vidro (35 L de volume útil), em um delineamento inteiramente casualizado (DIC), com densidade populacional de seis peixes cada. Durante este período, os peixes foram alimentados com ração comercial, fornecida três vezes ao dia, até a saciedade aparente. Em dias alternados, procedeu-se a troca parcial de água dos aquários para a retirada de matéria orgânica. Para garantir que a concentração salina se mantivesse condizente ao tratamento, realizou-se a reposição de água com quantidade de sal correspondente ao volume retirado, e a confirmação da concentração foi aferida por meio de refratômetro manual, com precisão de $1 \%$ (RFT0100 - ElecQueen ${ }^{\circledR}$ ).

Ao final de cada mês foram realizadas biometrias para acompanhamento do crescimento e avaliação dos índices de desenvolvimento dos peixes: peso e comprimento final e ganho em peso. Neste mesmo período, as sobras de ração de cada repetição foram pesadas, para o cálculo de consumo de ração. 
Observações visuais foram realizadas diariamente nos aquários para detectar possíveis alterações morfológicas e/ou comportamentais decorrentes do efeito das diferentes concentrações salinas propostas durante o ensaio.

Os dados obtidos foram submetidos à análise de variância (ANOVA) e quando diferentes significativamente, tiveram suas médias comparadas pelo teste de Tukey, ao nível de $5 \%$ de significância, utilizando procedimento GLM do SAS ${ }^{\circledR}$ (STATISTICAL ANALYSIS SYSTEM, 2013). Previamente ao teste comparativo entre médias, foram realizadas análises de normalidade e homocedasticidade das variâncias. Os dados de porcentagem de mortalidade foram transformados em arco-seno $\sqrt{\mathrm{x}} / 100$ para normalização da distribuição.

\section{RESULTADO}

A exposição dos peixes às salinidades de 12,5 e $15 \%$ resultaram em altas taxas de mortalidade durantes às 24 horas subsequentes ao choque osmótico, apresentando valores de 50 e $100 \%$, respectivamente (Tabela 1 ).

O valor de salinidade letal média (SL50) para os juvenis de pangasius foi estimado em $10,76 \%$ (IC $95 \%=10,22-11,33 \%$ ).

Tabela 1. Taxas de mortalidade (\%) de juvenis de pangasius (Pangasianodon hypophthalmus) em ensaio de toxicidade aguda à salinidade.

\begin{tabular}{llllcc}
\hline \multirow{2}{*}{ Tempo $(\mathrm{h})$} & 0 & 5 & 10 & 12,5 & 15 \\
\cline { 2 - 6 } & 0 & 0 & 0 & 50 & 100 \\
24 & 0 & 0 & 0 & 33 & - \\
48 & 0 & 0 & 4 & 17 & - \\
72 & 0 & 0 & 4 & - & - \\
\hline
\end{tabular}

$\mathrm{O}$ modelo de polinômio quadrático $\left(\mathrm{y}=0,8345 \mathrm{x}^{2}-5,0452 \mathrm{x}+0,0721 ; \mathrm{R}^{2}=0,839\right)$ foi $\mathrm{o}$ que melhor se ajustou à relação entre a taxa de sobrevivência e salinidade, de acordo com os resultados obtidos no ensaio de toxicidade aguda (Figura 1). 
Figura 1. Mortalidade média de juvenis de pangasius (Pangasianodon hypophthalmus), após 96 horas de exposição a diferentes salinidades.

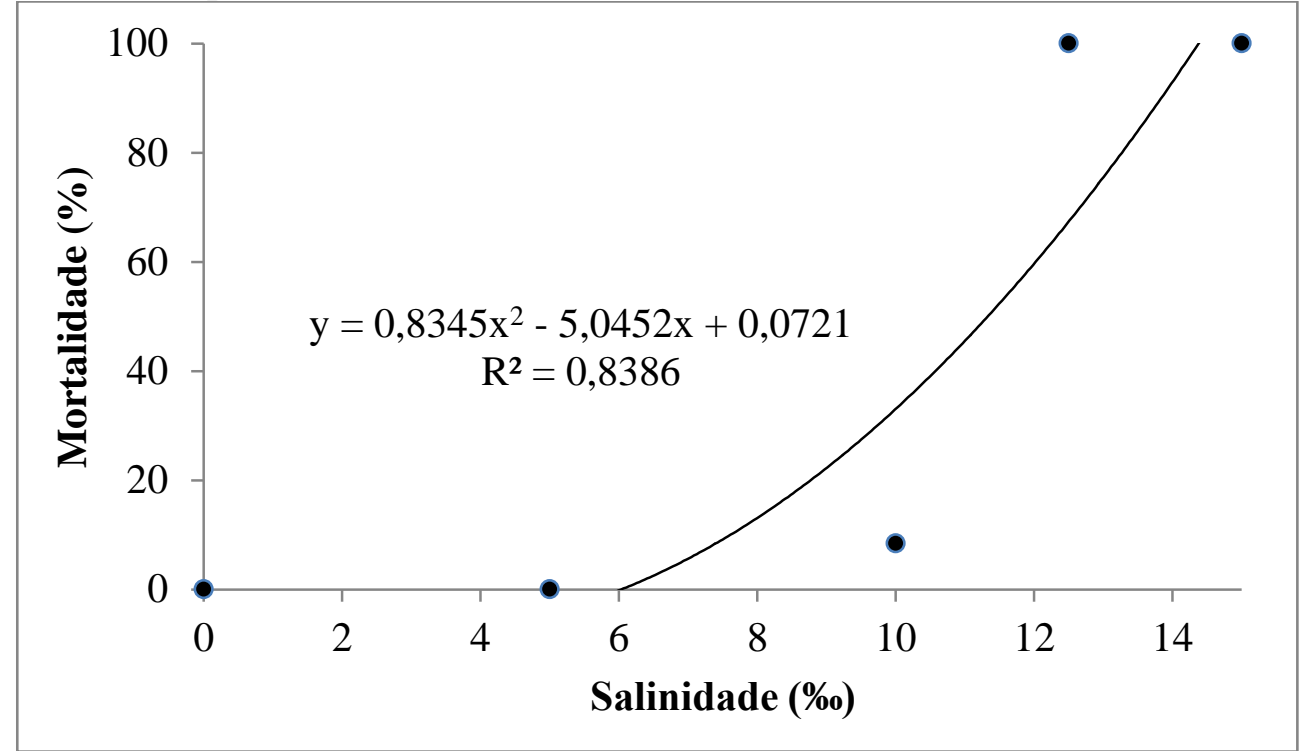

A salinidade é um importante parâmetro da água que pode influenciar de maneira significativa o crescimento, a fisiologia e o bem-estar dos peixes. De acordo com dados obtidos no presente estudo, não foram verificadas diferenças $(\mathrm{p} \geq 0,05)$ entre as médias de peso e comprimento final nas concentrações salinas estudadas (Tabela 2). Os peixes mantidos na concentração salina de $10 \%$ apresentaram menores taxas de consumo alimentar em relação à salinidade de 5\%, porém não diferiram em relação ao tratamento controle $(0 \%$ o e 7,5\%o. Maiores taxas de ganho de peso $(\mathrm{p}<0,05)$ foram observadas nas faixas de salinidade de 5 e $7,5 \%$.

Tabela 2. Índices de desenvolvimento de pangasius submetidos a diferentes salinidades.

\begin{tabular}{lllllllc}
\hline Salinidade $(\%)$ & PI $(\mathrm{g})$ & PF $(\mathrm{g})$ & CI $(\mathrm{cm})$ & CF $(\mathrm{cm})$ & Con. $(\mathrm{g})$ & G.P. $(\mathrm{g})$ & Mort. $(\%)$ \\
\hline 0 & 16,94 & 23,16 & 14,12 & 15,02 & $186,48 \mathrm{ab}$ & $6,73 \mathrm{~b}$ & 25,25 \\
5 & 16,02 & 24,45 & 13,46 & 14,96 & $191,81 \mathrm{a}$ & $8,30 \mathrm{a}$ & 8,34 \\
7,5 & 19,84 & 27,08 & 13,75 & 15,33 & $186,43 \mathrm{ab}$ & $7,46 \mathrm{a}$ & - \\
10 & 16,38 & 25,37 & 13,66 & 14,71 & $182,42 \mathrm{~b}$ & $6,52 \mathrm{~b}$ & 5,56 \\
\hline$P$ & 0,082 & 0,117 & 0,524 & 0,570 & 0,014 & 0,020 & 0,040 \\
CV $(\%)$ & 11,91 & 8,39 & 4,57 & 3,82 & 3,05 & 11,43 & 108,56 \\
\hline
\end{tabular}

PI: Peso inicial; PF: Peso final; CI: Comprimento inicial; CF: Comprimento final; Con.: Consumo; G.P: Ganho de peso; Mort.: Taxa de mortalidade. Médias seguidas de mesma letra na coluna não diferem entre si pelo teste de Tukey $(\mathrm{P} \geq 0,05)$.

Alterações morfológicas e comportamentais foram detectadas nos peixes do tratamento controle $(0 \%$ ) e nas salinidades de 7,5 e 10\%o (Tabela 3). As observações visuais incluíram natação errática, coloração corporal empalidecida, descascamento e erosões de pele. Menor 
presença de muco nas brânquias e na superfície corporal foi observada no tratamento controle. Observou-se a presença de pontos hemorrágicos nas nadadeiras dorsais e flexão das nadadeiras caudais, que, em alguns casos, se desintegravam na ocasião do manuseio. Redução da ingestão alimentar e inquietude foram respostas comportamentais frequentes dos peixes, exceto àqueles submetidos a concentrações de 5\% de sal marinho sintético. Adicionalmente, verificou-se a presença de inchaço abdominal e natação errática nos animais submetidos ao tratamento controle.

Tabela 3. Observações morfológicas e comportamentais de juvenis de pangasius (Pangasianodon hypophthalmus) submetidos à salinidade crônica.

\begin{tabular}{|c|c|c|c|c|}
\hline \multirow{2}{*}{ Observações } & \multicolumn{3}{|c|}{ Salinidade (\%o) } & \multirow[b]{2}{*}{10} \\
\hline & 0 & 5 & 7,5 & \\
\hline Morfológicas & $\begin{array}{c}\text { Coloração } \\
\text { normal; presença } \\
\text { de pontos } \\
\text { hemorrágicos } \\
\text { nas nadadeiras; } \\
\text { corrosão na } \\
\text { nadadeira } \\
\text { caudal; inchaço } \\
\text { abdominal. }\end{array}$ & $\begin{array}{l}\text { Coloração } \\
\text { normal; } \\
\text { nenhuma } \\
\text { alteração } \\
\text { morfológica. }\end{array}$ & $\begin{array}{c}\text { Coloração } \\
\text { pálida; presença } \\
\text { de pontos } \\
\text { hemorrágicos } \\
\text { nas nadadeiras e } \\
\text { boca; corrosão } \\
\text { na nadadeira } \\
\text { caudal. }\end{array}$ & $\begin{array}{c}\text { Coloração } \\
\text { pálida; presença } \\
\text { de pontos } \\
\text { hemorrágicos } \\
\text { nas nadadeiras e } \\
\text { boca; corrosão } \\
\text { nas nadadeiras } \\
\text { caudal e dorsal. }\end{array}$ \\
\hline Comportamentais & $\begin{array}{l}\text { Inquietude; } \\
\text { redução da } \\
\text { ingestão } \\
\text { alimentar; } \\
\text { natação errática. }\end{array}$ & $\begin{array}{c}\text { Nenhuma } \\
\text { alteração } \\
\text { comportamental. }\end{array}$ & Inquietude. & $\begin{array}{l}\text { Inquietude; } \\
\text { redução da } \\
\text { ingestão } \\
\text { alimentar. }\end{array}$ \\
\hline
\end{tabular}

\section{DISCUSSÃO}

Peixes teleósteos mantém a concentração osmótica do plasma em aproximadamente um terço em relação à água do mar (McCORMICK, 2011). No caso de espécies dulcícolas, isso requer a neutralização do ganho passivo de água e perda de íons por difusão, que é realizado através da produção de grandes volumes de urina diluída e absorção ativa de íons através das brânquias (BALDISSEROTTO, 2018). A concentração iônica da água pode se apresentar como um fator de estresse, interferindo negativamente nas taxas de crescimento, sobrevivência e nos parâmetros fisiológicos e comportamentais dos peixes (ALTINOK; GRIZZLE, 2001). Deste modo, a escolha de águas de cultivo com concentrações salinas adequadas podem promover melhorias significativas nas condições de produção de determinada espécie de interesse comercial.

Uma eficiente regulação iônica demanda um alto custo energético (ALTINOK; GRIZZLE, 2004). Um estudo realizado por BOEUF; PAYAN (2001) demonstrou que 20 a 50\% do gasto energético total de peixes teleósteos em condições de estresse são destinados a uma resposta 
especifica comum, na qual estes elevam os níveis de cortisol plasmáticos com a finalidade de regular o balanço osmótico.

Estudos demostraram que a salinidade elevada (até 10,5\%), provocou taxas de crescimento reduzidas em alevinos de carpas (WANG et al., 1997). Segundo Likongwe et al. (1996), salinidades elevadas podem ocasionar prejuízos na utilização de nutrientes da dieta durante o crescimento de juvenis de tilápia-do-Nilo, devido à grande energia despendida para manutenção da homeostase. No entanto, concentrações salinas baixas (em torno de 4\%o) têm se mostrado eficazes para a criação de larvas de peixes neotropicais (JOMORI et al., 2013).

Diante destas informações, o conhecimento da faixa de tolerância e adaptação de peixes de água doce a diferentes salinidades é de extrema importância para um bom rendimento zootécnico e bem-estar dos animais (TAKATA; LUZ, 2015). A faixa ideal de salinidade para o bom desenvolvimento da maioria dos teleósteos de água doce é geralmente menor que a concentração isotônica sanguínea (WURTS, 1995), sendo que estudos recentes apontaram que este valor é de aproximadamente 9\% para o pangasius (P. hypophthalmus) (DO; TRAN, 2012).

A salinidade letal média (SL50) encontrada para juvenis de $P$. hypophthalmus (10,76\%) no ensaio de choque agudo é condizente com aquelas obtidas com outras espécies de "catfish", tais como Clarias batrachus (SARMA et al., 2013), Clarias gariepinus (BRITZ; HECHT, 1989), Heteropneustes fossilis (AHMMED et al., 2017), Rhamdia quelen (FABREGAT et al., 2015) e o híbrido de Clarias gariepinus x Heterobranchus bidorsalis (GBULUBO et al., 2011).

Os peixes expostos ao choque agudo de salinidade em concentrações de 12,5 e 15\%o apresentaram altas taxas de mortalidade nas primeiras 24 horas (50 e 100\%, respectivamente). Estes resultados podem ser explicados em decorrência dos danos progressivos aos mecanismos de regulação osmótica dos peixes, ocorrendo perda excessiva de água, fazendo com que ocorra uma falha osmorregulatória (DEACON; HECHT, 1999). De acordo com Holiday et al. (1969), a sobrevivência dos peixes depende da capacidade dos mesmos em manter os fluidos corporais ao menos por um curto intervalo de tempo em uma faixa anormal de concentrações iônicas e osmóticas internas. Adicionalmente, Nguyen et al. (2014) relataram altos níveis de cortisol plasmático em pangasius mantidos em salinidades elevadas (14 e 18\%), sugerindo que esta espécie não apresenta uma boa capacidade de regulação osmótica.

Neste sentido, é importante salientar que os limites letais de salinidade obtidos através de testes agudos podem apresentar valores subestimados, uma vez que os peixes não sofrem aclimatação prévia, e, embora em condições naturais existam flutuações nos valores de salinidade, estas não ocorrem de maneira instantânea como os choques osmóticos realizados em condições laboratoriais (WU; WOO, 1983). De acordo com Miles e Smith (1968), os processos 
migratórios ou a transferência abrupta de peixes de água doce para água do mar promove elevações da concentração osmótica no soro sanguíneo dos peixes, bem como alterações em seu conteúdo iônico.

Consistente com nossos resultados, não foram observadas diferenças nas taxas de mortalidade de bagre-africano (Clarias gariepinus) cultivados em até 5\% de salinidade (BRITZ; HECHT, 1989) e de bagre-australiano (Heteropneustes fossilis) em 6\%o (AHMMED et al., 2017), em ensaios de tolerância crônica à salinidade. Diversos estudos com espécies de bagres de águadoce estenoalinos (i.e. que não suportam variações acentuadas de salinidade do meio) apontam que a exposição em longo prazo a salinidades acima de 10\%o afetam negativamente a sobrevivência e o crescimento dos peixes (CLAY, 1977; BABIKER et al., 1984; GBULUBO et al., 2011; SARMA et al., 2013; AHMMED et al., 2017; KUMAR et al., 2017).

Em estudo recente, Kumar et al. (2017) relataram que o pangasius pode sobreviver em água salgada em uma concentração de até 15\%, enquanto taxas de $100 \%$ de mortalidade foram observadas em salinidades de 20 e 25\%. De maneira semelhante, Castaneda et al. (2010) verificaram que esta mesma espécie pode ser cultivada em águas com salinidades de até 13\%o, sem afetar negativamente seu crescimento, podendo sobreviver por um período de até 22 dias em salinidades de até 20\%o. As observações supracitadas divergem dos resultados obtidos no presente experimento, onde se observou que os peixes apresentaram capacidade de sobrevivência em salinidades de até 10\%o. Segundo Nguyen et al. (2014), o pangasius perde potencialmente sua capacidade osmorregulatória quando a salinidade excede $10 \%$, impactando negativamente as taxas de sobrevivência e o crescimento. Neste ponto, deve-se salientar que, embora a tolerância à salinidade seja uma resposta espécie-específica, esta é variável de acordo com diversos fatores, entre eles o tamanho dos peixes e o tempo de exposição (TAKATA; LUZ, 2015).

\section{CONCLUSÃO}

A partir da presente investigação pode-se concluir que a exposição em longo prazo em águas com salinidade elevada (acima de 10\%) afeta o desenvolvimento de juvenis de pangasius. Os peixes exibiram uma melhor taxa de crescimento sem exibirem alterações morfológicas e comportamentais em salinidades de 5\%. Estes resultados são promissores, uma vez que os níveis de salinidade de água em muitos reservatórios da região semiárida do país permanecem próximos dentro desta faixa, sugerindo que o pangasius poderia ser uma espécie candidata para o cultivo. No entanto, como o presente estudo foi conduzido em condições laboratoriais, destaca-se a necessidade de um maior número de experimentos de campo para uma melhor compreensão da tolerância ao estresse salino e o correto manejo para o aumento da produtividade desta espécie. 


\section{AGRADECIMENTOS}

Os autores agradecem à Colpani Piscicultura, pela doação dos peixes utilizados neste experimento; à empresa Fundo do Mar Aquários, pela doação do sal marinho sintético; e à Associação Brasileira de Criadores de Pangasius (ABC Panga) pelo apoio.

\section{REFERÊNCIAS}

AHMMED, M. K.; AHMMED, F.; KABIR, K. A.; FAISA, M.; AHMED, S. I ; AHSAN, M. N. Biochemical impacts of salinity on the catfish, Heteropneustes fossilis (Bloch, 1794), and possibility of their farming at low saline water. Aquaculture Research, v.48, n.8, p.4251-4261, 2017. https://doi.org/10.1111/are.13246

ALTINOK, I.; GRIZZLE, J.M. Effects of brackish water on growth, feed conversion and energy absorption efficiency by juveniles euryhaline and freshwater stenohaline fishes. Journal of Fish Biology, v.59, p.1142-1152, 2001. https://doi.org/10.1111/j.1095-8649.2001.tb00181.x

ALTINOK, I.; GRIZZLE, J. M. Excretion of ammonia and urea by phylogenetically diverse fish species in low salinities. Aquaculture, v.238, p.499-507, 2004.

https://doi.org/10.1016/j.aquaculture.2004.06.020

AMEND, D.F.; CROY, T.R.; GOVEN, B.A.; JOHNSON, K.H.; MCCARTHY, D.H.

Transportation of fish in closed systems: methods to control ammonia, carbon dioxide, $\mathrm{pH}$, and bacterial growth. Transactions of the American Fisheries Society, v. 111, p.603-611, 1982.

BABIKER, M. M. Aspects of the biology of the catfish Clarias lazera (Cuv. ; Val.) related to its economic cultivation. Limnology and Marine Biology in the Sudan, p. 295-304, 1984.

https://doi.org/10.1007/bf00025801

BALDISSEROTTO, B. Osmorregulação. In: BALDISSEROTTO, B. (e.d.) Fisiologia de peixes aplicada à piscicultura, Santa Maria: Ed. da UFSM, 2018, p.95-137.

BOEUF, G.; PAYAN, P. How Should Salinity Influence Fish Growth? Comparative Biochemistry and Physiology-Part C: Toxicology ; Pharmacology, v.130, p.411-423, 2001. https://doi.org/10.1016/S1532-0456(01)00268-X

BRITZ, P.J.; HECHT, T. Effect of salinity on growth and survival of African sharptooth catfish (Clarias gariepinus) larvae. Journal of Applied Ichthyology, v.5, p.194- 202, 1989.

https://doi.org/10.1111/j.1439-0426.1989.tb00492.x

CARNEIRO, P.C.F.; URBINATI, E.C. Salt as a stress response mitigator of matrinxã, Brycon cephalus (Günther), during transport. Aquaculture Research, v.32, p.297-304, 2001.

http://dx.doi.org/10.1046/j.1365-2109.2001.00558.x

CASTANEDA, M.M.; MARIO, V. Pangasius juveniles tolerate moderate salinity in test. Global Aquaculture Alliance, p.27-28, 2010.

CHAGAS, E. C.; ARAÚJO, L. D.; GOMES, L. C. MALTA, J. C. O.; VARELlA, A. M. B. Efeito do cloreto de sódio sobre as respostas fisiológicas e controle de helmintos monogenóides 
em tambaqui (Colossoma macropomum). Acta Amazonica, v. 42, n.3, p.439-444, 2012. http://dx.doi.org/10.1590/S0044-59672012000300017

CLAY, D. Preliminary observations on salinity tolerance of Clarias lazera from Israel. Bamidgeh, v.29, p.102-109, 1977.

DEACON, N.; HECHT, T. The effect of reduced salinity on growth, food conversion and protein efficiency ratio in juvenile spotted grunter, Pomadasys commersonnii (Lacépède) (Teleostei: Haemulidae). Aquaculture Research, v.30, p.13-20, 1999. https://doi.org/10.1046/j.13652109.1999.00281.x

DO, T.T.H., TRAN, N.T.Q. The effect of salinity on the embryonic development and osmoregulatory of the striped catfish (Pangasianodon hypophthalmus) larvae and fingerling stages. Journal of Science - Can Tho University, Vietnam 21b, p.29-37, 2012.

EMERSON, K., R.C. RUSSO, R.E. LUND, AND R.V. THURSTON. Aqueous Ammonia Equilibrium Calculations: Effects of $\mathrm{pH}$ and Temperature, Journal of the Fisheries Research Board of Canada, vol. 32, p. 2379-2383, 1975.

FABREGAT, T.E.H.P.; DAMIAN, J.; FIALHO, N.S. COSTA, D. BROGGI, J.A.; PEREIRA, R.G.; TAKATA, R. Toxicidade aguda ao sal comum e larvicultura intensiva do jundiá Rhamdia quelen em água salobra. Arquivo Brasileiro de Medicina Veterinária e Zootecnia, v.67, n.2, p.547-554, 2015. http://dx.doi.org/10.1590/1678-7660

GBULUBO, A. J.; GABRIEL, U. U.; NWADUKWE, F. O. Mortality of hybrid catfish (Clarias gariepinus $x$ Heterobranchus bidorsalis) fingerlings at varying salinity levels. Journal of Fisheries International, v.6, p.71-74, 2011. http://dx.doi.org/10.3923/jfish.2011.71.74

HAMILTON, M.A.; RUSSO, R.C.; THURSTON, R.V. Trimmed Spearman-Karber method for stimating median lethal concentrations in toxicity bioassays. Environmental Science and Technology, v.11, p.714-719, 1977. https://doi.org/10.1021/es60130a004

HOLIDAY, P. G. D. Effect of salinity on the eggs and larval of teleost. Fish Physiology, v.1, p.293-312, 1969. https://doi.org/10.1016/S1546-5098(08)60085-0

JOMORI, R.K.; LUZ R.K.; TAKATA, R.; FABREGAT, T.E.H. P.; PORTELLA, M.C. Água levemente salinizada aumenta a eficiência da larvicultura de peixes neotropicais. Pesquisa Agropecuária Brasileira, v.48, p.809-815, 2013. https://doi.org/10.1590/S0100204X2013000800001

KADER, M. A.; BULBUL, M.; YOKOYAMA, S.; ISHIKAWA, M.; KOSHIO, S.; HOSSAIN, M.S.; AHMEDG, U.; HOSSAIN, M. A. Evaluation of meat and bone meal as replacement for protein concentrate in the practical diet for Sutchi Catfish, Pangasius hypophthalmus (Sauvage 1878), reared under pond condition. Journal of the World Aquaculture Society, v. 42, p. $287-$ 296, 2011. https://doi.org/10.1111/j.1749-7345.2011.00466.x

KUBITZA, F. A versatilidade do sal na piscicultura. Panorama da aquicultura, set./out. p. 1423, 2007.

KUMAR, A.; HARIKRISHNA, V.; REDDY, A.K.; CHADHA, N.K.; BABITHA RANI, A.M. Salinity tolerance of Pangasianodon hypophthalmus in inland saline water: Effect on growth, 
survival and haematological parameters. Ecology, Environment and Conservation, v.23, n.1, p. 475-482, 2017.

LIKONGWE, J.S.; STECKO, T.D.; STAUFFER Jr., J.R.; CARLINE, R.F. Combined effects of water temperature and salinity on growth and feed utilization of juvenile Nile tilapia Oreochromis niloticus (Linneaus). Aquaculture, v.146, p.37-46, 1996.

https://doi.org/10.5829/idosi.wjz.2014.9.1.8414

McCORMICK, S. D. The hormonal control of osmoregulation in teleost fish. In: FARRELL A. P. (ed.), Encyclopedia of fish phisiology: from genome to environment, San Diego: Academic Press, v.2, 2011, p.1466-1473.

MILES, H. M.; SMITH, L. S. Ionic regulation in migrating juvenile Coho Salmon, Oncorhynchus kisutch. Comparative Biochemistry Physiology, v.26, p.381-398, 1968. https://doi.org/10.1016/0010-406X(68)90633-6

NGUYEN, P.T.H.; DO, H.T.T; MATHER, P.B.; HURWOOD, D.A. Experimental assessment of the effects of sublethal salinities on growth performance and stress in cultured tra catfish (Pangasianodon hypophthalmus). Fish Physiology and Biochemistry, v.40, p.1839-1848, 2014. https://doi.org/10.1007/s10695-014-9972-1

NGUYEN, T.H.P.; MATHER, P.B.; HURWOOD, D.A. Effects of sublethal salinity and temperature levels and their interaction on growth performance and hematological and hormonal levels in tra catfish (Pangasianodon hypophthalmus). Aquaculture International, v. 25, p.10571071, 2017. https://doi.org/10.1007/s10499-016-0097-7

PHUONG, N.T.; OANH, D.T.H. Striped Catfish Aquaculture in Vietnam: A Decade of Unprecedented Development. In: Silva, S.S.; Davy, F.B. (eds.): Success Stories in Asian Aquaculture. Springer Netherlands, 2010. p.131-147

REISH, D.L.; OSHIDA, P.S. Manual of methods in aquatic environment research, Part 10: short-term static bioassays, v.247, 1-62, 1987.

SAOUD, P. I.; KREYDIYYEH, S.; CHALFOUN, A.; FAKIH, M. Influence of salinity on survival, growth, plasma osmolality and gill $\mathrm{Na}^{+}-\mathrm{K}^{+}-$ATPase activity in the rabbitfish Siganus rivulatus. Journal of Experimental Marine Biology and Ecology, v.348, p.183-190, 2007. https://doi.org/10.1016/j.jembe.2007.05.005

SARMA, K.; PRABAKARAN, K.; KRISHNAN, P.; GRINSON, G.; KUMAR, A.A. Response of a freshwater air-breathing fish, Clarias batrachus to salinity stress: an experimental case for their farming in brackishwater areas in Andaman, India. Aquaculture International, v.21, p.183-196, 2013. https://doi.org/10.1007/s10499-012-9544-2

SAS INSTITUTE Inc. SAS/STAT. User's guide, version 9.1. Cary: SAS Institute, 2013.

TAKATA, R.; LUZ, R. K. Água salinizada na produção de peixes de água doce. In Aquicultura no Brasil: novas perspectivas. São Carlos, 2015, v. 2, p. 523-544.

TAVARES-DIAS, M.; MONTAGNER, D. Uso e principais aplicações do sal comum na piscicultura de água doce. Embrapa Amapá (Série Documentos 195), Macapá, AP. 30 p. 2015. 
URBINATI, E. C. ; CARNEIRO, P. C. F. Sodium chloride added to transport water and physiological responses of matrinxã Brycon cephalus (TELEOST: CHARACIDAE). Acta Amazonica, v.36, p.569-572, 2006. http://dx.doi.org/10.1590/S0044-59672006000400020

WANG, J. Q.; LUI, H.; PO, H.; FAN, L. Influence of salinity on food consumption, growth and energy conversion efficiency of common carp (Cyprinus carpio) fingerlings. Aquaculture, v. 148, p.115-124, 1997. http://dx.doi.org/10.1016/S0044-8486(96)01334-8

WU, R.S.S.; WOO, N.Y.S. Tolerance of hypo-osmotic salinities in thirteen species of adult marine fish: implications for estuarine fish culture. Aquaculture, v.32, p.175-181, 1983. https://doi.org/10.1016/0044-8486(83)90279-X

WURTS, W.A. Using salt to reduce handling stress in channel catfish. World Aquaculture, v.26, p.80-81, 1995. 